\title{
An international programme for famine relief
}

\section{By G. D. Kapsiotis, Food Policy and Nutrition Division, United Nations Food and Agriculture Organization, 00100 Rome, Italy}

'Within one decade no child will go to bed hungry, no family will fear for its next day's bread, and no human being's future and capacities will be stunted by malnutrition'. Presidents, Prime Ministers, Ministers of Foreign Affairs, of Agriculture and other policy makers of 127 countries of the world accepted this herculean goal. They also solemnly proclaimed that 'Every man, woman and child has the inalienable right to be free from hunger and malnutrition... Society today possesses sufficient resources, organizational ability and technology and hence the competence to achieve this objective.... The eradication of hunger is a common objective of all the countries of the international community ... 2 This goal was set and this proclamation was made in November 1974 at the World Food Conference (WFC) in Rome.

Never in history have the policy makers of the world come to grips with the problem of hunger and made a solemn pledge to eliminate it. It is true that some 30 years ago the Food and Agriculture Organization (FAO) of the United Nations was created aiming at exactly the same goal. Yet a generation later more people than ever go hungry and more preventable famines break out in alarming succession. Dr Adekke Boerma spoke yesterday (Boerma, 1975) on the war against hunger during these last 30 years and gave an account of what had been done or, better, of what had not been achieved. I would like only to underline that the vocation of the Good Samaritan existed and still exists, but the political will to eradicate hunger and prevent famine has been poor or altogether absent. Let us hope that the WFC of the United Nations will help to strengthen this political will where it exists and generate it where it is absent.

Famine relief denotes an action of mending and it has a connotation of charity and defeatism. Relief just means an easing of a somewhat difficult situation, but it does not give the feeling of aggressive action to correct, to redress or to eliminate altogether an unacceptable situation. I was therefore happy when I saw and read the recent book by Dr Wallace Aykroyd, my former Director and colleague in FAO, entitled The Conquest of Famine (Aykroyd, 1974). Personally I am allergic to the word 'relief' as far as it concerns famine. It is easy to throw the responsibility for famine on irresponsible factors like weather, floods, drought, hail, frost, war or on whatever you like, but the ultimate responsibility resides on the human-but not always humane-society. As Dr Aykroyd says in his book: 'Unlike an earthquake, a famine is rarely a sudden emergency. It is usually a long-drawn-out calamity in which supplies of food dwindle for months or more, from restriction to scarcity and in due course to complete dearth'. This does mean that famine, unless 
due to unpredictable catastrophes, can be averted, and can be prevented by both short-term and long-term programmes.

The experience of the relief operations in Sahel, in Bangladesh and in other less spectacular, but all the same dramatic, situations have pointed out a number of direct and indirect factors which render the relief operations ineffective, unwelcome and in certain instances politically dangerous. And of course this is to be expected since relief operations have to be organized at a moment's notice. The main non-governmental relief organizations have been performing a marvellous, dedicated work either in isolation or very often in co-ordination with the concerned specialized agencies (United Nations Children's Fund (UNICEF), FAO and the World Health Organization (WHO)) of the United Nations system as well as with governmental bodies. But predictable bureaucratic delays coupled with loose coordination leave much to be desired for quick and effective action.

There are instances where, even if the preparatory phase was organized to perfection, difficulties in monitoring the proper use of supplies or of assessing the impact defeated in a large measure the emergency intervention. Ethnic and political rivalries, waste and discrimination in distribution have led to gross inequities in the provision of foods to various groups (Sheets \& Morris, 1974) and minimized the relief from tragedy.

The co-ordination within a region or group of countries affected by famine can be a determining factor in relief planning and execution. For example, it has been reported (Brun, 1974) that during the height of the Sahel crisis exports of groundnuts from the famine-stricken area had not been modified at all. These could have been of assistance to starving populations. It would have been conceivable to divert part of the $1971-2$ groundnut production, which was relatively good, towards the regions menaced by famine. However, this did not happen. Obviously, under no circumstances could well-established interests have been touched.

What I am trying to say is that famines can be prevented and averted. It takes above all sensible planning, based on early warning, co-ordination, adequate if not perfect knowledge of the infrastructure of the area menaced and, most important the political will of both donors and receivers to face seriously and with complete freedom from internal and external pressures the existing or approaching tragedy.

Such an expression of political will has been made at the WFC in Rome. Should a dynamic follow-up of its resolutions be undertaken, the foundation for preventing and averting famine can definitely become a reality. The omens appear to be favourable, since shortly after the conference some wheels were set in motion.

While it can be said that the resolutions adopted by the WFC do not constitute a self-contained programme for famine relief, they do provide the elements for making the international society able to face successfully both short-term and longterm shortages of food.

I will attempt to highlight those resolutions which have a bearing on the prevention of famine and, if you like, on famine relief. The conference adopted some twenty resolutions (UN Economic and Social Council, 1974), emanating from the basic conclusions that the solution of the world food problem required co- 
ordinated action on three important points: to increase food production, especially in developing countries; to build a system of food security; to improve consumption and distribution of food.

In order to assist developing countries to increase their food production the conference calls on governments of these countries to accord a high priority to agricultural and fisheries development. It also decided to call for the immediate establishment of an International Fund for Agricultural Development. The implementation of many of the specific action programmes and policies to transform the agriculture of developing countries will definitely require large investment by these countries and a greatly increased flow of financial resources from outside. Concurrently, in order to increase, co-ordinate and improve the efficiency of financial and technical assistance to agricultural production, the conference requested the United Nations Development Programme (UNDP), the World Bank and FAO to organize a Consultative Group on Food Production and Investment in Developing Countries. This last is already being established.

The conference stressed the urgent need for establishing on a world-wide basis a Global Information and Early Warning System on Food and Agriculture. This system is now being set up by FAO in consultation and co-operation with other concerned international organizations like the World Meteorological Organization, the International Wheat Council, WHO and others. The system aims at identifying countries and regions where acute food shortages and malnutrition problems are thought to be imminent; at monitoring conditions of world food supply and demand; and finally at contributing to the effective functioning of the International Undertaking on World Food Security.

The concept of the World Food Security met with strong support by the Conference, which endorsed the proposal of the Director-General of FAO for the creation of an International Undertaking on World Food Security, which I have just mentioned. The central feature of this undertaking is that countries should adopt national stockholding policies in order to arrive at and maintain at least a minimum safe level of basic food stocks, principally cereals, for the world as a whole. The availability of such supplies at any given time is urgently needed in order to avoid acute food shortages in the event of widespread crop failure, natural and other disasters, to improve the food consumption and nutritional status in countries with low per capita food intake and to offset fluctuations in production and prices. While FAO has been active in promoting this undertaking, an Intergovernmental Consultation on World Food Security to be held late this month will set the pace and extent of action to be taken.

I would like at this stage to refer to three important recommendations addressed to UN Agencies concerning particularly the improvement of nutrition and health. The first is that governments, whether of developing or developed countries, should formulate intersectoral food and nutrition plans. As Dr Boerma stated in the Boyd Orr Memorial Lecture (Boerma, 1975), in so far as the problem of world hunger is basically an economic problem, nutrition must be regarded as an integral part of the framework of economic planning. At the request of the WFC, FAO, in co-operation with WHO, UNICEF, UNDP, the World Food Programme (WFP), 
the World Bank and the United Nations Educational, Scientific and Cultural Organization, is preparing a programme to assist interested governments in this type of food and nutrition planning. The second recommendation on which FAO, WHO and UNICEF are already at work concerns the establishment of a Global Nutrition Surveillance System. The objective of this system is to monitor the food and nutrition conditions of disadvantaged groups of the population at risk, and to provide a method of rapid and permanent assessment of all factors which influence food consumption patterns and nutritional status. The third recommendation is to provide assistance to governments for emergency programmes providing supplementary feeding of malnourished children.

The actual and potential role of the WFP was considered with particular attention by the conference. It was recommended that the WFP Intergovernmental Committee (FAO, 1963) be entrusted with the task of formulating proposals for more effective co-ordination of multilateral, bilateral and voluntary food aid programmes, and of co-ordinating emergency food aid. It was further recommended that part of the emergency stocks of the International Undertaking be placed at the disposal of the WFP, on a voluntary basis, in order to increase its capacity for speedy assistance in emergency situations.

I referred earlier to the primordial importance of political will to solve the world food problem, to provide food for all. The WFC, in order to furnish political strength for follow-up action, called for the formation of a World Food Council at ministerial-political level. This council, already in existence, is an organ of the United Nations General Assembly serviced within the framework of FAO, with its headquarters in Rome. It is given the responsibility and directive to initiate, to supervise and co-ordinate the implementation of the recommendations and decisions of the WFC.

In the meantime and most probably always, unpredictable disasters, whether man-made or God-sent, will always occur. Shortages or complete lack of food along with other essentials for survival will emerge. The international community, with its spirit of the Good Samaritan, will be alerted and we hope supplies of everything needed will be available. Experience in Sahel, Bangladesh, Biafra, Ethiopia and elsewhere demonstrated that the countries hit by disaster do not and cannot have the infrastructure essential to meet the emergency. Organizations like the International Red Cross, Co-operative for American Relief Everywhere, Catholic Relief Services and others have already developed a substantial knowledge of how to handle emergency situations. However, their influence and efficiency very often is limited to the point where the ship enters the port, the plane lands at the airport or the truck convoy reaches the borders of the disaster-stricken country. I do not think it appropriate at this forum to enter into polemics but I want to stress the fact that national sovereignty has to be respected and the national machinery is not always equipped to deal with emergencies even if they have been occurring in succession.

To assist the national machine in coping with emergencies with some measure of success and efficiency the Protein Advisory Group of the United Nations System commissioned the preparation of a 'Manual on Food and Nutrition in 
Emergencies'. This manual will be for the use, at a national level, of relief administrators, government officials, non-governmental welfare organizations and field staff charged with relief operations. At the international level the manual will be for the use of donor governmental agencies, voluntary organizations and the United Nations System of Organizations.

The objective of the manual is to provide guidelines, clear instructions and information regarding the planning, administration and co-ordination of food and nutrition relief operations. Particular treatment will be given to the logistics and technical aspects of food relief operations, an area which was not adequately covered by the handbook Food and Nutrition Procedures in Times of Disaster (FAO, 1967 ).

This is the state of preparedness of the international community to face food shortages, famine and certainly malnutrition. It does not appear to be a clear-cut international programme tailored to famine relief on which I have been invited to address this meeting. But I am sure you would agree with me that the elements for such a programme are factual and accessible. Famine relief, no matter how massive and spectacular it might be, is only a palliative. What is needed is: more food available over the years for every mouth, equitable distribution of food for everyone, a monitoring system and the means for quick and efficient intervention to avert disasters. Is this wishful thinking? Is it Utopia? Of course miracles do not occur. Spectacular achievements are not to be expected for they are, in any event, deceiving and have a very short life. At the international level, the expression of political will, voiced during the WFC, should be translated into action if there is a real intent to bring about the hoped-for change. It is the political will within a nation which will decide whether investments, efforts, ingenuity will be devoted to food and agricultural production and to the improvement of the nutrition and health of its people, or to meet the needs of other sectors of the economy or to satisfy the requirements of national prestige or pride. It is for governments and policy makers of the international community to decide whether famine will be conquered through the policies and programmes they set up in Rome last year.

\section{REFERENCES}

Aykroyd, W. R. (1974). The Conquest of Famine. London: Chatto \& Windus.

Boerma, A. H. (1975). Proc. Nutr. Soc. 34, 146.

Brun, T. (1974). Cah. Nutr. Diet. 9, 2.

$\mathrm{FAO}$ (1963). World Food Programme Intergovernmental Committee General Regulations. Rome: FAO.

FAO (1 967). F.A.O. Nutr. Stud. no. 21.

Sheets, H. \& Morris, R. (1974). Disaster in the Desert: Failures in International Relief in the West African Drought. Washington, DC: The Camegie Endowment for International Peace.

UN Economic and Social Council (1974). World Food Conference: Document E/5587. Rome: UN Economic and Social Council. 